\title{
O analista , desconcertado? ${ }^{1}$
}

\author{
Plinio Montagna ${ }^{2}$
}

\section{Psicanálise}

O analista vive de desconcertos. De pequenos desconcertos. De desconcertos maiores. De gradações de desconcertos. De desconcertos em geral, na acepção da palavra. ${ }^{3}$

De que tratam eles? O que fazer com eles? Como torná-los um bom negócio, não os deixando arrastar-nos para o polo do traumático, mas sim utilizando-os para instrumentar nosso fazer?

Grandes ou pequenos desconcertos, ultrapassá-los depende de pontos de vista. Foi o que argumentou o arquiteto Fillippo Brunelleschi (1377-1446), quando chamado a construir a cúpula da catedral de Santa Maria dei Fiori, em Florença, no século XV, convocado por Cosimo de Médici. Obra há cem anos inconclusa, por sua complexidade e dimensões, seu diâmetro, pouquíssimos acreditava que pudesse ser terminada.

Brunelleschi convenceu os céticos através da relativização do que parecia absoluto : pra principiar, usou a teoria da perspectiva, e mostrou que um objeto pequeno pode aparentar ser muito grande ou muito pequeno conforme a luz e o ponto a partir do qual observamos. A ele também se atribui o uso da manobra que ficou conhecida entre nós como "ovo de Colombo".

Até hoje, mais de quinhentos anos após sua construção, esse domo permanece sendo a maior cúpula de alvenaria já construída.

Assim é que quando tratamos da apreensão de desconcerto, entra em cena a perspectiva que tomamos para tal. Nossa própria subjetividade só pode ser observada com um grau de subjetividade.

Em certo sentido, o desconcerto do analista vem a ser o seu próprio concerto, retornando à antítese que vem a constituir a origem da palavra. ( lutar, disputar ) . Concerto, do latim com + certare = lutar, competir; disputar, debater, passou, a partir do italiano, a significar trazer em harmonia, desenvolvendo conotações

\footnotetext{
${ }^{1}$ Este trabalho foi apresentado em oficina sobre as plenárias no I Simpósio Bienal "O mesmo, o outro: Psicanálise em movimento" eixo "O analista desconcertado: mal estar e cínica" da Sociedade Brasileira de Psicanálise de São Paulo.

${ }^{2}$ Analista Didata e ex-presidente da SBPSP, chair do Comitê Psicanálise e Lei.

${ }^{3}$ A palavra desconcerto refere-se a desordem, desarmonia, desarranjo, transtorno, discordância, perturbação, embaraço. Com alguma superposição semântica à sua semelhante desconserto, guarda uma etimologia própria . Vem, desconcertar (des + concertar), do latim concertāre, este com o sentido de combater, lutar, disputar, sentido que se estendeu a harmonizar, ajustar, uma vez que uma luta visa um ajuste. Nesse sentido, temos concertação social para nos referirmos a ligação entre partes, acordos diversos, consensos - e o sentido musical já no século XIX. ${ }^{3}$
} 
musicais específicas de harmonia. ( Ayko, 2005 ) ${ }^{4}$. $\quad$ O contrário do concerto, o desconcerto, assim, implica na des-harmonia, des-arranjo.

O fato é que desconcerto e concerto se imbricam, tem uma área de sobreposição, e não só do ponto de vista etimológico-semântico. No âmbito do fazer do analista, é nessa área de trânsito dos dois, na oscilação concerto $\langle>$ desconcerto, tal qual a oscilação Ps < > D, é que nos movemos do a- simbolismo para a gramática dos símbolos, da não figurabilidade à figurabilidade, e novamente à não figurabilidade, e assim por diante num fluxo espitalar. É essa contenda consigo mesmo, essa luta interna implicada na palavra concerto, que categoriza o desconcerto do analista.

É o esquizoparanóide que se configura como necessário à posição depressiva do insight que configura o ser, a atividade necessária para a ação analítica. E assim como a aproximação a um aroma novo e inusitado modifica toda a circuitaria olfativa cerebral de modo que a nova aquisição passa a constituir parte integrante do sistema, com vistas a novos aromas, também uma nova aquisição através de um insight modifica nossos sistemas no contato com novos estímulos afetivo-cognitivos com o mundo.

Quando o aumenta a indeterminação, a desordem, a difusão de estímulos, de certo modo aumenta a entropia de um sistema e menor a quantidade de informações; de certo modo, aumenta o desconcerto. Mas para nós analistas a indeterminação, a desordem, a difusão de estímulos, a percepção do próprio desconcerto são, ao contrario da teoria da informação propriamente dita, preciosas informações a serem valorizadas. Tudo mudou desde o reconhecimento do trabalho do analista com suas reações pessoais,

De modo que desconcertos são parte da atividade analítica por excelência, do ofício do analista, cujo trato pode levar a dupla a um encontro, à iluminação de um insight, ou não. O desconcerto é a situação da mente do analista antes de juntar os elementos para formular uma intervenção, consciente ou mesmo inconsciente .

Para tanto há que se respeitar e ultrapassar a(s) cesura (s), eventuais e não eventuais. Esta(s), a(s) cesura (s), não dependem de nós. Já originariamente o termo, que se referia se à pausa em verso ou linha de uma poesia após a qual o verso continua, não depende do leitor. Tem métricas determinadas, que os dividem em segmentos melódicos e que independem de quem a aprecia. ( Moises, 2004 ).

Assim, cesura implica em interrupção e continuidade, na prosódia clássica, conotando mais especificamente um tipo específico de interrupção, como apontamos, em uma linha ou um verso, após a qual o verso continua. Numa música, é uma pausa ou respiração em um ponto da divisão rítmica da melodia.

Freud e Bion falam da cesura pré / pós-natal, que é um modelo para transpor cada intervalo, cada interrupção, espaço, e para descobrir a continuidade entre acontecimentos que parecem tão díspares. O modelo da sinapse para pensá-la (Bion,

\footnotetext{
${ }^{4}$ A argumentação é que a contenda anterior levou a uma harmonia , daí por exemplo o termo concertação social
} 
1977) permite entendê-la como um hiato no qual coexistem a ruptura (separação entre um neurônio e outro) e a comunicação (entre eles, através dos neurotransmissores). Estamos no âmbito da separação/união entre eu e o outro, sujeito e objeto, entre diferentes estados mentais ainda que pareçam intransponíveis entre si. Estamos no terreno do movimento e da separação, superposição e transposição de desconcerto/concerto, da mente do analista, e entre este e seu analisando, mesmo porque que aquele não existe sem este. Fazem-se valer as barreiras de contato.

Não se pode esquecer do desconcerto/ desconcerto, da cesura mente/corpo, do contato com estados mentais arcaicos, eventualmente traços de vivências somáticas ligadas ao ego corporal, irrepresentadas até o encontro a capacidade de tornar figurável da dupla . A mãe pode captar a comunicação de fome, de terror, de solidão, de satisfação, de seu bebê.

O modelo da cesura, parafraseando Bergstein (2014) é o do rio caudaloso entre duas margens. A ser transposto, é o lugar da mudança catastrófica mas onde também reside o perigo de catástrofe.

Sabemos de Bion que não se trata de passar de uma margem à outra, mais segura, mas na oscilação PS $<>$ D, Concerto $<>$ Desconcerto, de ampliar o fluxo entre elas , bidirecionalmente .

Estamos numa área de indeterminação e surpresa, no qual as ocorrências são imprevisíveis e a criatividade pode brotar (ou, ao contrário, pode vencer o descarrilamento e o trauma). A incerteza implícita nas esferas intrapsíquica e intersubjetiva abrem campo para se criar. Quanto mais imprevisível (e talvez mais desconcertante) o campo, maior, talvez, a criatividade. É impossível se determinar quando será deflagrado um lampejo criativo, ou aquele que, como veremos adiante, vai caracterizar o ponto de inflexão do percurso, questão esta que, confesso, sempre me intrigou.

Não de trata na psicanálise, como ocorre na teoria da informação, de sustentar que desordem (e, portanto, desconcerto), falta de clareza e precisão da mensagem aumentam a entropia e diminuem a quantidade de informações. Trata-se sim, no campo psicanalítico, de romper com esta leitura, talvez levando mais em conta elementos sensoriais (ver Ogden em seu trabalho sobre posição autística-contígua) e abrindo a porta para que prevaleça nossa intuição.

De todo modo, o que vem a existir não existia antes e não poderia ser previsto em sua totalidade por nenhum dos parceiros. Ressalte-se que nem toda criatividade, porém, se revela construtiva para a dupla ou mesmo para o desenvolvimento do paciente. Aqui é relevante o discernimento, e aquilo que se costumava denominar de "timing".

$\mathrm{O}$ analista vive também de desconcertar

\section{Beethoven}

Os primeiros sintomas de surdez de Ludwig Van Beethoven, um dos maiores compositores musicais de todos tempos, começaram em 1796, aos 26 anos de idade. 
Eles evoluíram até a surdez, que o levou a se isolar e influiu nas depressões que enfrentou. No início supôs que se tratava de um mal passageiro, mas aos poucos sua audição foi minguando. Em 1801 a situação tornou-se alarmante. Escreveu ao seu médico e médico e amigo Franz Wegeler: "Durante dois anos procurei evitar a companhia de todos, simplesmente porque não posso dizer que estou surdo. Se eu tivesse outra profissão, tudo seria mais fácil, mas com o meu trabalho esta situação é terrivel".

Em profunda crise existencial e amargor, sentia toda sua vida ameaçada. Cogitou seriamente o suicídio. No ano seguinte, viajou a descanso a um povoado próximo a Viena, Heilingenstadt, onde escreveu o que ficou conhecido como "Testamento de Heiligenstadt", uma carta manuscrita, encontrada só depois da sua morte, em que reflete, desesperado, a tragédia da sua surdez:

Ó homens que me tendes em conta de rancoroso, insociável e misantropo, como vos enganais. Não conheceis as secretas razões que me forçam a parecer deste modo... Meu coração e meu ânimo sentiam-se desde a infância inclinados para o terno sentimento de carinho e sempre estive disposto a realizar generosas ações; porém considerai que, de seis anos a esta parte, vivo sujeito a triste enfermidade... Iludido constantemente, na esperança de uma melhora, fui forçado a enfrentar a realidade da rebeldia desse mal ... Nascido com um temperamento vivo e ardente, sensível mesmo às diversões da sociedade, vi-me obrigado a isolar-me numa vida solitária. Por vezes, quis colocar-me acima de tudo, mas fui então duramente repelido, ao renovar a triste experiência da minha surdez!

Como confessar esse defeito de um sentido que devia ser, em mim, mais perfeito que nos outros, de um sentido que, em tempos atrás, foi tão perfeito como poucos homens dedicados à mesma arte possuíam... Para mim, já não há encanto na reunião dos homens, nem nas palestras elevadas, nem nos desabafos íntimos. Só a mais estrita necessidade me arrasta à sociedade. Devo viver como um exilado...

... Esses incidentes levaram-me quase ao desespero e pouco faltou para que, por minhas próprias mãos, eu pusesse fim à minha existência. ... Só a arte me amparou! Pareceu-me impossível deixar o mundo antes de haver produzido tudo o que eu sentia me haver sido confiado, e assim prolonguei esta vida infeliz....

…

Minha gratidão a todos os meus amigos.. Recebo com felicidade a morte. Se ela vier antes que realize tudo o que me concede minha capacidade artística, apesar do meu destino, virá cedo demais e eu a desejaria mais tarde. Entretanto, sentir-me-ei contente pois ela me libertará de um tormento sem fim. ... Heiligenstadt, 6 de outubro de 1802.

A crescente disfunção de seu mais precioso sentido, a audição, transtorna seu mundo, avaria sua existência, desconcerta seu ser, a ponto de querer a morte. É neste fundo, no contexto da perda total, que algo brota, um ponto de inflexão que o conduz, através do uso de toda a sua criatividade, para a vida. "Foi a arte, e apenas ela que me 
reteve", disse ele. "Parecia impossível deixar o mundo antes de ter dado tudo o que germinava em mim".

O compositor deixou o povoado de Heiligenstadt, meses depois, com a partitura de sua monumental Sinfonia $\mathrm{n}^{\mathbf{0}} 3$, Eroica - a qual aparece, assim, depois da crise fundamental de sua existência.

Seu desconcerto progrediu até um extremo, ${ }^{5}$ quando houve uma inversão: todas as forças de vida dão vazão a toda a potência de sua criatividade genial, organizando uma síntese de sons e silêncios musicais que vieram a constituir numa das maiores peças musicais já compostas. da humanidade.

Entre o descarrilamento traumático e a resposta criativa trafegam as perspectivas diante do desconcerto, sejam elas de cada um de nós como analistas, que a rigor dele também vivemos, seja da Psicanálise de modo amplo, trilhas novas a serem percorridas.

O próprio desenvolvimento humano se dá no trabalho dialético de harmonia/desarmonia.

\section{O Banquete}

Com esses contornos nos apresentamos a este banquete, na feliz analogia de Mariano Horenstein. Lembremos que todos os povos da antiguidade possuíam os seus banquetes. Via de regra portavam consigo, para esses, suas histórias, seus mitos, suas crenças, fantasias, seus deuses. Assim nos atestam os preciosos afrescos do belíssimo museu etrusco de Villa Giulia, vizinho a Flaminio, em Roma.

Assim é conosco também, ao nos reunirmos na perspectiva de trabalhar uma psicanálise viva, com voz influente neste mundo de desenvolvimento tecnológico tal que alguns vaticinam uma passagem ao pós-humano, como configura Yuval Harari em seu brilhante Homo Deus.

Esta, a chama da psicanálise, usando a clara expressão evocada por Marcio Giovannetti, de certo modo se confunde com a chama do humano, (ver Poland). Para se manter acesa, deve acompanhar os caminhos, seus trajetos, suas peculiaridades.

Não há desconcerto fora de um contexto. Ou melhor, às vezes é exatamente o desconcerto do analista que altera o rumo, rompe com um campo e cria outro, como dizia Fabio Herrmann, ou se está diante da eclosão de uma situação limite, a qual por seu turno traz à tona aquilo que já existia em potencial, ou se está diante de uma perspectiva de mudança, com ou sem catástrofe. E dá-se que aquele contexto abriu caminho para o novo, de certo modo embalado, trabalhado, transubstanciado no fazer do desconcerto do analista, o qual por sua vez, não raro pode desconcertar o analisando com suas associações improváveis.

Nesse contexto, diante do incerto futuro, resta-nos apegarmo-nos às nossas capacidades negativas, conviver com as inevitáveis incertezas, mistérios, dúvidas,

\footnotetext{
5 Um ponto de inflexão
} 
quanto a nosso futuro, "sem qualquer buscar exasperadamente fato ou razão (Bion, 1970, p. 125) ", servindo-nos de nossas experiências emocionais, de nossa razão e de nossa intuição para de nosso desconcerto criar e manter elementos, não fugazes, de reflexão consistente para sustentar nossas ações perante o mundo contemporâneo. Está em jogo a resiliência da psicanálise e do psicanalista.

\section{Referências}

Aito, J. (2005) - Words Origins. London, A \& C Black.

Bergstein, a. (2014) - Transpor a cesura: Reverie, Sonhar e Sonhar na Contratransferência. Livro Anual de Psicanálise, XXIX, 129-151

Boston Change Proccess Study Group (2005) - The Something More than Interpretation Revisited: Sloppiness and Co-creativity in the Pschoanalytic Encounter. Journal of the American Psychoanalytic Association, 53(3):693-729

Bion, W. R. (1970) - Attention and Interpretation. London, Karnac, 1984

Bion, W. R. (1977) - Caesura. In: Two papers: The Grid and the Caesura. London, Karnac, 1989.

Freud, S. (1915) - The Unconscious. Standard Edition 14, 159-215.

Moises, M. (2004) - Dicionário de Termos Literários. São Paulo, Cultrix. 